\title{
Design and Simulation of InP and Silicon Nanowires With Different Channel Characteristic as Biosensors to Improve Output Sensitivity
}

shahramm mohammad nejad ( $\sim$ shahramm@iust.ac.ir)

Iran University of Science and Technology https://orcid.org/0000-0002-1818-3023

Iman Tahi

Iran University of Science and Technology School of Electrical Engineering

Mahdiyar Nouri Rezaie

Iran University of Science and Technology School of Electrical Engineering

\section{Research Article}

Keywords: SiNWs, InPNWs, Biosensor, Analyte, SILVACO TCAD

Posted Date: June 22nd, 2021

DOI: https://doi.org/10.21203/rs.3.rs-450822/v1

License: (c) (i) This work is licensed under a Creative Commons Attribution 4.0 International License.

Read Full License 
Design and simulation of InP and silicon nanowires with different channel characteristic as biosensors to improve output sensitivity

\author{
Shahram Mohammadnejad*, Iman Tahi and Mahdiyar Nouri Rezaie
}

Department of Electrical Engineering, Iran University of Science and Technology, Narmak, Tehran, Iran

*Corresponding author Tel: +98 21 73225630, Fax: +98 2173225777

P.O. Box: 1684613114, Narmak, Tehran, Iran

E-mail address: Shahramm@iust.ac.ir 


\section{Abstract}

This research contains a good comparison among technologies of SiNW-FET/InPNW-FET depending on the size of channel and dopants in channel for biosensing application based on the width and dopants for two types of silicon and InP materials in the nanowire channel. A device numerical modelling tool, Silvaco ATLAS is used in step one to design three p-type SiNWFET/InPNW-FET biosensors with a channel width of $40 \mathrm{~nm}, 60 \mathrm{~nm}$ and $70 \mathrm{~nm}$ for these two types of materials and in step two to design three p-type SiNW-FET/InPNW-FET biosensors with different dopants of $0.1 \times 10^{14} \mathrm{~cm}^{-3}, 1 \times 10^{14} \mathrm{~cm}^{-3}$ and $10 \times 10^{14} \mathrm{~cm}^{-3}$ for these two types of materials. Their sensing process is depended on the alteration in charge density that causes changing in the electric field at the surface of the SiNW-FET/InPNW-FET. The resistivity of the device is changed when a negatively charged biomolecules species has a chemical reaction with the external surface of a P-type SiNW-FET/InPNW-FET. To investigate the effect of different channel width and dopants on the performance of the SiNW-FET/InPNW-FET biosensor, several negatively interface charge densities, $Q_{\mathrm{F}}\left(-0.1 \times 10^{12} \mathrm{~cm}^{-2},-0.5 \times 10^{12} \mathrm{~cm}^{-2}\right.$, and $-1 \times 10^{12} \mathrm{~cm}^{-}$ ${ }^{2}$ ) are introduced on the surface of the SiNW-FET/InPNW-FET channel to represent as the actual target analytics (DNA) captured by the bioreceptor of the biosensor. Based on the results, these negatively $\mathrm{Q}_{\mathrm{F}}$ attract the hole carriers below the surface of p-type nanowire causes to collect carriers in the channel, and make an increase in the device output $\mathrm{I}_{\mathrm{D}}$. Increase of the applied negative charge density has allowed for more $\mathrm{I}_{\mathrm{D}}$ to flow across the channel between drain and source region. The changes of $\mathrm{I}_{\mathrm{D}}$ with the applied $\mathrm{Q}_{\mathrm{F}}$ are utilized to determine the sensitivities for all designed biosensor with different channel width and channel dopants. The minimum nanowire width of $40 \mathrm{~nm}$ with the minimum nanowire dopants of $0.1 \times 10^{14} \mathrm{~cm}^{-3}$ for the high sensitivity silicon state of $3.6 \mu \mathrm{A} / \mathrm{cm}^{-2}$ compared to the indium phosphide state of $2.8 \mu \mathrm{A} / \mathrm{cm}^{-2}$. So the best performance for detecting the desired analyte in the silicon state with the lowest width and dopant to be seen.

\section{Keywords:}

SiNWs, InPNWs, Biosensor, Analyte, SILVACO TCAD. 


\section{Introduction}

Nano sensors have been recently one of the most appropriate methods for rapid analysis of body cells $[1,2]$. The common chemical detection techniques are insufficient because of its kind of detection and on-site recognition[2]. Besides, high accuracy and precision of biological and chemical species recognition and measurement are very crucial in the medical diagnostics and environmental monitoring fields, which can be provided with the utilization of biosensor[3]. To meet this requirement, the exploitation of semiconductor nanostructures as a promising piece to be integrated in biosensing application $[4,5]$ has been considered by researchers in the recent years. Among them, silicon nanowire field-effect transistor (SiNW-FET/InPNW-FET) has emerged and attracted attention to be applied in designing a biosensor due to their extremely high sensitivity, selectivity, real-time detection, and label-free [6]. SiNW-FET/InPNW-FET sensors are a kind of transistors (FET)-based devices, which contains of source, drain and gate electrodes. The sensing of this kind of transistor is like the other ones when changing in charge density, causes changing in the electric field at the SiNW-FET/InPNW-FET surface. For example, biomolecules with a negative charge on the surface of a p-type FET causes changing in the device resistance [2]. Because of the large surface-to-volume, electrical properties, and incompatibility, the SiNWFET/InPNW-FET have been a good detector with ultrasensitive and selective property [6]. The typical FET-based device consists of three electrodes, named as drain, gate, and source. The source and drain electrodes are connected together by a channel made of SiNW-FET/InPNWFET, while the gate electrode is responsible for the modulation of channel conductance [7]. The sensing mechanism of the device is based on the difference in charge density originated from the bounded target analyte at the SiNW-FET/InPNW-FET exterior surface and causes the change of electric field at the channel. The resistance of the device may increase or decrease which effect on the electrical conductivity/resistivity of 1-D nanostructures between electrodes $[8,9]$.

Recently development of electrochemical biosensors in nano devices has been understood in many areas medical investigations[10], environmental checking, industrial testing and etc. A 
nano biosensor is integrated for detecting a sample by a chemical receptor in contact with a transmitter (Fig. 1a). Recently nanomaterials, like quantum dots, nanowires, carbon nanotubes, and nano films $[11,12]$, have a good effects on the future of nano biosensors. For instance, the dimension of nanowires of 1-10 nm contains a good property to detect specifications of the most biological entities, like DNA, nucleic, proteins, viruses, bacterium and cells (as illustrated in Fig. 1b)

(a)
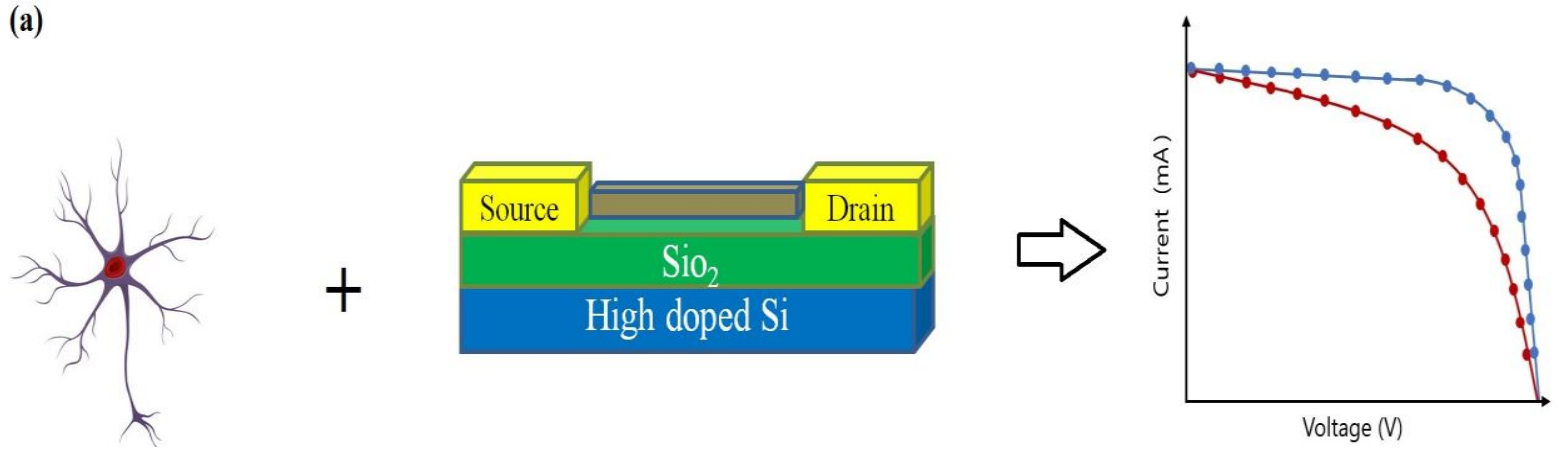

(b)

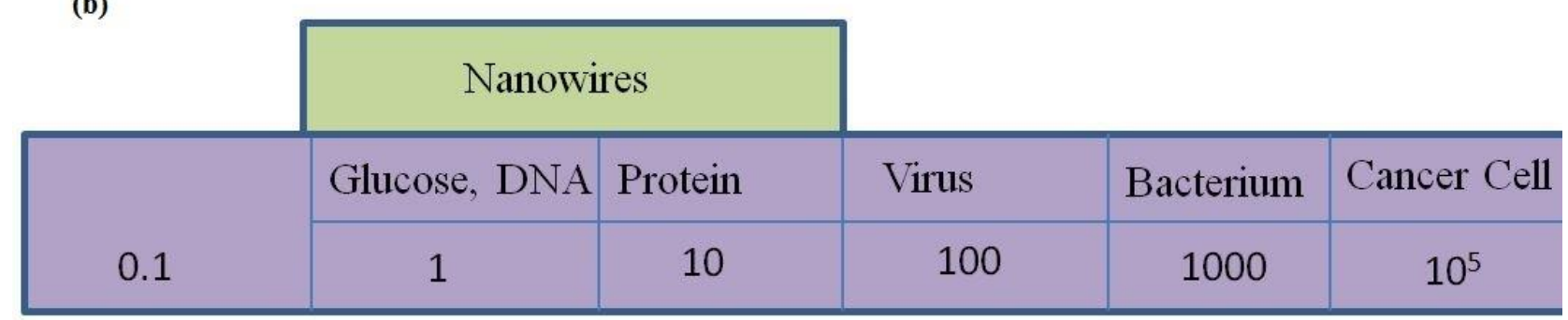

Fig. 1 (a) Biological recognition element; (b) Dimension of nanowire.

In order to better understand the performance of nanosensors, we should understand relation between the potential at the gate oxide surface and the amount of analyte (PH) in the electrolyte[13]. An electrical layer (EL) is defined between solid and liquid interfaces. The potential at the gate is shown with $\Psi$ s and depends on the chemical reactions as in Eq. (1) $[14,15]$ :

$$
\Psi_{\mathrm{s}}=\sigma \mathrm{s} / \mathrm{Cd}
$$

In this relation $\sigma \mathrm{s}$ is the density of surface-charge and Cd is the capacity of EL zone.

The reaction between the charged particles with the gate surface oxide changes the voltage ( $\Psi_{s}$ ), which is in relation with the threshold voltage (Vth) of the TFT[16]. In a Si TFT, SiO2 in gate oxid 
consists of $\mathrm{Si}-\mathrm{OH}$ as hydroxyl groups are affected by the absorption or repulsion of protons that is affected by the $\mathrm{pH}$ value of the electrolyte solution. This absorption or repulsion causes readjust in ionic component of the electrolyte and at last in the constitution of an EL with a certain distance from the gate. The shape of the EL can be shown by complicated models like the Gouy-Chapman-Stern theory in Fig. 2. The EL applies surface potential accumulation to the oxide surface, which is then the $\mathrm{pH}$ can be sensed with this mechanism. This potential $\left(\Psi_{\mathrm{s}}\right)$ is in a direct relation with $\mathrm{pH}$ value in the electrolyte solution, $\Psi_{\mathrm{s}}=\mathrm{f}(\mathrm{pH})[17]$.

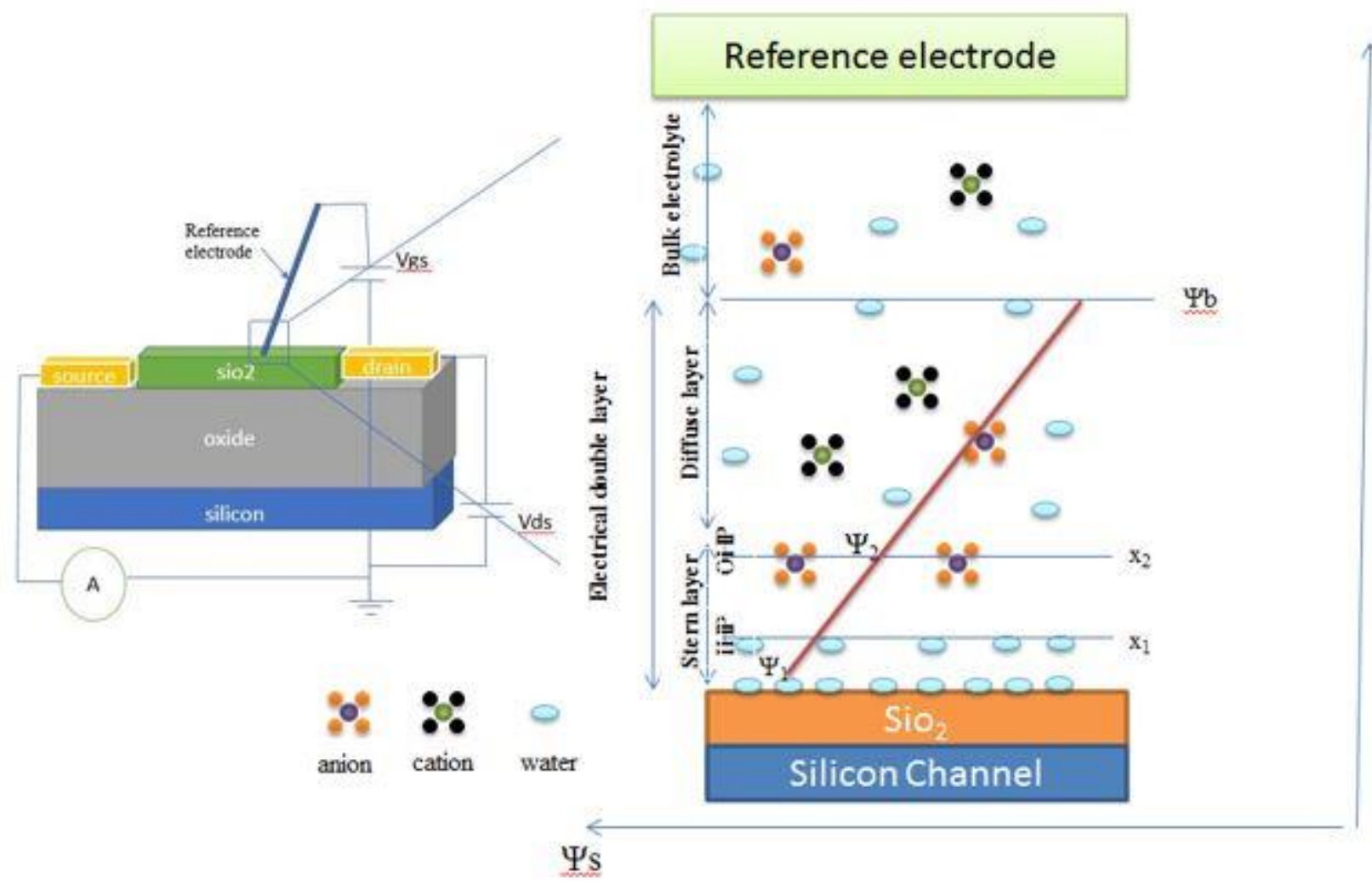

Fig. 2 Diagram of the electrical layer (EL) consists of the Stern layer and the diffuse layer. The potential decreases linearly inside the EL.,The diagram is also showing the potential distribution within the TFT and the electrical layer near the oxide/electrolyte interface ( $\Psi \mathrm{s})$.

The acid/base reactions happens between the gate oxide surface with hydroxyl groups ( $\mathrm{Si}-\mathrm{OH})$ and the hydrogen ions $(\mathrm{H}+)$ in the electrolyte solution with this model, which is described with Ka and $\mathrm{K}_{\mathrm{b}}$ as follows Eq. (2), Eq. (3) [18]:

$$
\mathrm{Si}-\mathrm{OH}_{2}^{+} \leftleftarrows \mathrm{Si}-\mathrm{OH}+\mathrm{H}^{+}, \mathrm{K}_{b}=\frac{[\mathrm{Si}-\mathrm{OH}]\left[\mathrm{H}^{+}\right]_{s}}{\left[\mathrm{Si}-\mathrm{OH}_{2}^{+}\right]}
$$




$$
\mathrm{Si}-\mathrm{OH} \leftleftarrows \mathrm{SiO}^{-}+\mathrm{H}^{+}, K_{a}=\frac{\left[\mathrm{SiO}^{-}\right]\left[\mathrm{H}^{+}\right]_{S}}{[\mathrm{Si}-\mathrm{OH}]}
$$

We can see that $\left[\mathrm{H}^{+}\right]_{\mathrm{s}}$ is the activity of the ions at the surface and as the surface units per area.

The charges from the surface with zero potential in the bulk area of the solution form the potential at the solid-liquid zone. This absorption or repulsion of hydroxyl groups in oxide surface causes the $\mathrm{H}+$ ion concentration varies at the both of solid-liquid interface and bulk electrolyte solution [18]. The Boltzmann distribution shows that the gate surface with $\mathrm{H}+$ ions $([\mathrm{H}+] \mathrm{s})$ and $\mathrm{PH}_{\mathrm{s}}$ is in relation with the bulk electrolyte with $\mathrm{H}^{+}$ions $\left(\left[\mathrm{H}^{+}\right]_{\mathrm{b}}\right)$ and $\mathrm{PH}_{\mathrm{b}}$ by Eq. (4), Eq. (5), Eq. (6), Eq. (6), Eq. (7)[18]:

$$
\begin{aligned}
& {\left[H^{+}\right]_{s}=\left[H^{+}\right]_{b} \exp \left(-\frac{q \Psi_{s}}{K T}\right)} \\
& p H_{s}=p H_{b}+\frac{q \Psi_{s}}{2.3 k T} \\
& p H_{s}=-\log _{10}\left[H^{+}\right]_{s} \\
& p H_{b}=-\log _{10}\left[H^{+}\right]_{b}
\end{aligned}
$$

We assume $\mathrm{q}$ as the primary charge, $\mathrm{k}$ as the Boltzmann constant and $\mathrm{T}$ as the absolute temperature. Ns is the total density from level sites at the gate oxide and determine as Eq. (8)[15]:

$$
N_{s}=[\mathrm{Si}-\mathrm{OH}]+\left[\mathrm{SiO}^{-}\right]+\left[\mathrm{Si}-\mathrm{OH}_{2}^{+}\right]
$$

The parameters $\mathrm{K}_{\mathrm{a}}, \mathrm{K}_{\mathrm{b}}$ and Ns is in relation with the type of gate insulator.

$\sigma_{\mathrm{s}}$ is the surface-charge density with the difference in number of positively charged groups and negatively charged groups per unit area as Eq. (9) [19]:

$$
\sigma_{s}=q\left(\left[\mathrm{Si}-\mathrm{OH}_{2}^{+}\right]-\left[\mathrm{SiO}^{-}\right]\right)=q N_{s}\left(\frac{\left[H^{+}\right]_{s}^{2}-K_{a} K_{b}}{K_{a} K_{b}+K_{b}\left[H^{+}\right]_{s}+\left[H^{+}\right]_{s}^{2}}\right)=-q[B]
$$

The point of zero charge(the number of positively charged groups equals the number of negatively charged) in Eq. (10) is in $\mathrm{pH}_{\mathrm{pzc}}=2$ for $\mathrm{SiO} 2$ as gate oxide, the point of zero charge is $[\mathrm{B}]=\sigma_{\mathrm{s}}=0$. [15]. 


$$
\mathrm{pH}_{\mathrm{pzc}}=\left(\mathrm{pK}_{\mathrm{a}}+\mathrm{pK} \mathrm{b}\right) / 2
$$

Dividing Eq. (9) with pHs gives Eq. (11)[18]:

$$
\frac{\partial \sigma_{\mathrm{s}}}{\partial p H_{s}}=-q \frac{\partial[B]}{\partial p H_{s}}=-q \partial \beta_{\mathrm{int}}
$$

Bint, measures the chargeability of the oxide surface by changing the $\mathrm{pH}$ [20] value of the solution. It is in relation with the intrinsic properties of the surface, $N_{s}, K_{a}$ and $K_{b}$.

At the EL because of the charge neutralization condition, an equal value of charge density $\sigma_{E L}$ appears with the opposite pole on the electrolyte side of the layer.

As you can see in Fig. 2, the EL is formed of several layers(the Stern layer and the diffuse layer (DL)) depending on the distribution of ionic ingredient of the electrolyte[18]. At a distance of $x 1$ from the gate oxide adsorbate ions and molecules that is close to the gate oxide is called the inner Helmholtz (IHP) (Fig. 2). The surface-charge density os on the gate oxide which can only approach the oxide level up to a distance of $\mathrm{x} 2$ is balanced by dissolved ions. The outer Helmholtz plane (OHP) is the area between the IHP and the nearest available solvated ions. DL area is between the OHP and the bulk of the electrolyte where the value of the solvated ions decreases. Electrostatic force or higher ionic strength electrolyte causes the increasing of interaction between the surface charge and the solvated ions and form a thinner DL. The potential inside the Stern layer decreases with incresing of distance between the gate oxide surface and the electrolyte solution. In the following the potential into the DL zone decreases until become near zero (Fig. 2, red curve) in the bulk solution ( $\Psi$ b). There is another potential, between the unmoved ions of the Stern layer and the moving ions of the DL with $\Psi 2$, (Fig. 2). There are a parameter as Debye length $\left(\lambda_{D}\right)$ that ilustrate the distance from the oxide surface in the electrolyte solution, in this area the potential decreases from its real value in the gate oxide[21]. For a given electrolyte solution, $\lambda_{\mathrm{D}}$ can be calculated by Eq. (12)[15]:

$$
\lambda_{D}=\sqrt{\frac{\varepsilon_{0} \varepsilon_{r} K T}{2 q^{2} P}}, P=\frac{1}{2} \sum c_{i} z_{i}^{2}
$$


$\varepsilon r$ is the dielectric constant of the electrolyte solution, $\varepsilon 0$ is the vacuum permittivity, $\mathrm{P}$ is the ionic strength of the electrolyte and the concentration of ions in the electrolyte solution display with ci and zi.

The surface-charge density $\sigma \mathrm{s}$ is in relation by charges in the electrolyte side of EL $\left(\sigma_{\mathrm{EL}}\right)$ (as shown in Fig. 2) as Eq. (13) [18]:

$$
\sigma_{\mathrm{s}}=-\sigma_{E D L}=\sigma_{O H P}+\sigma_{D L}
$$

$\sigma_{\mathrm{OHP}}$ and $\sigma_{\mathrm{DL}}$ show the charge densities in the OHP and DL, respectively.

At last, the charge is in relation with the capacitance in this area( $\left.\mathrm{C}_{\mathrm{EDL}}\right)$ by Eq. (14), Eq. (15)[18].

$$
\begin{aligned}
& \sigma_{\mathrm{s}} \approx C_{E D L} \Psi_{s} \\
& \frac{\partial \sigma_{\mathrm{s}}}{\partial \Psi_{s}} \approx C_{d}
\end{aligned}
$$

With Cd capacitance, combining Eqs. (11) and (15), the dependence of $\Psi$ s on the pHb can be obtained as Eq. (16)[18]:

$$
\frac{\partial \Psi_{s}}{\partial_{P} P H_{b}}=-2.3 \frac{K T}{q} a, a=\frac{1}{1+2.3 \frac{K T C_{d}}{q^{2} \beta_{i n t}}}
$$

We can see that there is a direct relation between the $\mathrm{pH}$ sensitivity of the TFT and the charging behavior of oxides. In this model the site-dissociation developed by Yates is used to describe the FET sensitivity[18].

So because of the relation in charging and dimensional properties we can also understand relation in the sensitivity with the variation of silicon nanowire (SiNW) width (Wsi) and doping[22] and compare it with InP nanowire(InPNW), on the other hand to compare the different effects of channel width and doping in these two materials, the electrical characteristics of the part have been designed according to the proximity of their properties in Table 1. 
Table. 1 Comparing the property of $\mathrm{Si}$ with $\mathrm{InP}$

\begin{tabular}{|c|c|c|}
\hline Material & SI & InP \\
\hline Carrier type & $\mathrm{P}, \mathrm{N}$ & $\mathrm{P}$ \\
\hline $\mathbf{E g}(\mathbf{e V})$ & 1.1 & 1.344 \\
\hline Dielectric constant & 11.7 & 12.5 \\
\hline Carrier density $\left(\mathbf{g} / \mathbf{c m}^{\mathbf{3}}\right)$ & 2.328 & 4.81 \\
\hline Crierar mobility $\left(\mathbf{c m}^{\mathbf{2}} / \mathbf{V s}\right)$ & 500 & 200 \\
\hline $\mathbf{p I}$ & $3.2(\mathrm{SiO} 2)$ & $3.2(\mathrm{SiO} 2)$ \\
\hline Dimension $\mathbf{( n m})$ & $(\mathrm{D}) 5-30$ & $(\mathrm{D}) 5-31$ \\
\hline $\begin{array}{c}\text { Hydrophobicity/ } \\
\text { hydrophilicity }\end{array}$ & Hydrophilic & Hydrophilic \\
\hline Stability & Stable & Stable \\
\hline \multicolumn{2}{|c|}{} \\
\hline
\end{tabular}

So, one of the aspects that may influence the sensitivity of the FET device is the wire size, which is highly related to the surface-to-volume ratio. For an example, if charged analyte is applied to a thick wire, only specific area located at or near to the wire surface with the exception to the interior site of the wire will be affected by the applied electric field originated from the charged target analyte [23]. On the other hand, when the diameter of the wire is decreased down to nanoscale, the surface-to-volume ratio can be drastically improved and the entire nanowire cross-section area could be influenced by the external electric field and exceptional change in induced conductance can be achieved inside the SiNW-FET/InPNW-FET [24, 25]. The high quality of the SiNW-FET/InPNW-FET is essential to limit the distribution of charge carriers on the sidewalls and, thus enable for high electrical conductance and sensitivity of the NW [26].

As an alternative, two ways that may improve the performance of p-type SiNWFET/InPNW-FET biosensor is by optimizing the width and dopants of the nanowire[27]. In this paper, the effect of different channel width and dopants on electrical characteristic of the SiNWFET/InPNW-FET biosensor is investigated via simulation in Silvaco ATLAS device modelling tool. In step one SiNW-FET/InPNW-FET biosensors with several channel widths of $40 \mathrm{~nm}, 60$ $\mathrm{nm}$ and $70 \mathrm{~nm}$ are designed and simulated and in step two with several channel doping of $0.1 \times 10^{14} \mathrm{~cm}^{-3}, 1 \times 10^{14} \mathrm{~cm}^{-3}$ and $10 \times 10^{14} \mathrm{~cm}^{-3}$ are designed and simulated to observe the changes in the electrical resistance and output drain current $\left(\mathrm{I}_{\mathrm{D}}\right)$ of the device and at last both of them combine to achieve the best result. Furthermore, the SiNW-FET/InPNW-FET biosensor is 
introduced with several negative interface charge densities, $Q_{F}$ including $-0.1 \times 10^{12} \mathrm{~cm}^{-2}$, $-0.5 \times 10^{12} \mathrm{~cm}^{-2}$, and $-1 \times 10^{12} \mathrm{~cm}^{-2}$ on the surface of channel to represent target biomolecule [28, 29] for every simulated channel width/dopants, in order to observe their impact on the I-V characteristic and hole concentration beneath the surface of the SiNW. Finally, the sensitivities of the SiNW-FET/InPNW-FET biosensors with different channel width and dopants are determined to get the best result [30]. The result should suggest an appropriate choice of channel width and dopants of SiNW-FET/InPNW-FET for future biomedical application in biosensing.

\section{Research methodology}

The simulation is started by declaring the structure of the SiNW-FET(InPNW-FET) biosensor through the use of specific ATLAS commands, such as mesh, region, electrode, doping, and etc. Silicon (Si) with low p-type doping concentration of $1 \times 10^{14} \mathrm{~cm}^{-3}$ is utilized as the biosensor's substrate. A $145 \mathrm{~nm}$ thick silicon dioxide $\left(\mathrm{SiO}_{2}\right)$ layer is used as an electrical passivation layer known as buried oxide (BOX) on top of the substrate layer. Next, another Si layer with thickness of $44 \mathrm{~nm}$ is deposited on the surface of the BOX to become the top-Si device layer. In the following two designes is considered.

\subsection{Different channel width}

The top-Si layer is doped with p-type dopant at concentration of $1 \times 10^{14} \mathrm{~cm}^{-3}$. It is then patterned in order to form three regions, which are source, drain, and channel of the SiNWFET(InPNW-FET) biosensor. The source and drain regions are patterned with the length and width of $500 \mathrm{~nm} \times 500 \mathrm{~nm}$, while the channel region with different channel width of $40 \mathrm{~nm}, 60$ $\mathrm{nm}$, and $70 \mathrm{~nm}$ is patterned from the top-Si layer to bridge the drain and source, the length of the $\operatorname{SiNW}(\mathrm{InPNW})$ is kept constant at $1 \mu \mathrm{m}$ for all channel width designs [31]. In order to provide a biomolecule interaction area, another layer of $\mathrm{SiO}_{2}$ with thickness of $15 \mathrm{~nm}$ is covered on the surface of the SiNW-FET(InPNW-FET) channel. The surface of drain and source pads are deposited with $40 \mathrm{~nm}$ thick aluminum and $100 \mathrm{~nm}$ thick cobalt layer to provide 
electrodes for the device.

\subsection{Different channel doping}

The top-Si layer is doped with p-type dopant at concentration of $0.1 \times 10^{14} \mathrm{~cm}^{-3}, 1 \times 10^{14} \mathrm{~cm}^{-3}$, $10 \times 10^{14} \mathrm{~cm}^{-3}$ in order to understand the effect of the channel doping on the performance of the biosensor. It is then patterned in order to form three regions, which are source, drain, and channel of the SiNW-FET(InPNW-FET) biosensor. The source and drain regions are patterned with the length and width of $500 \mathrm{~nm} \times 500 \mathrm{~nm}$, while the channel region width of $40 \mathrm{~nm}$ is patterned, the length of the $\operatorname{SiNW}(\mathrm{InPNW})$ is kept constant at $1 \mu \mathrm{m}$ for all channel doping designs [31]. In order to provide a biomolecule interaction area, another layer of $\mathrm{SiO}_{2}$ with thickness of $15 \mathrm{~nm}$ is covered on the surface of the $\mathrm{SiNW}(\mathrm{InPNW})$ channel. The surface of drain and source pads are deposited with $40 \mathrm{~nm}$ thick aluminum and $100 \mathrm{~nm}$ thick cobalt layer to provide electrodes for the device.

Fig. 3a shows the cross-sectional structure views of the SiNW-FET biosensor is designed in Silvaco ATLAS. In the next step, instead of using silicon in the relevant channel, indium phosphide is used as InPNW-FET, which can be seen in Fig. $3 b$.

(a)

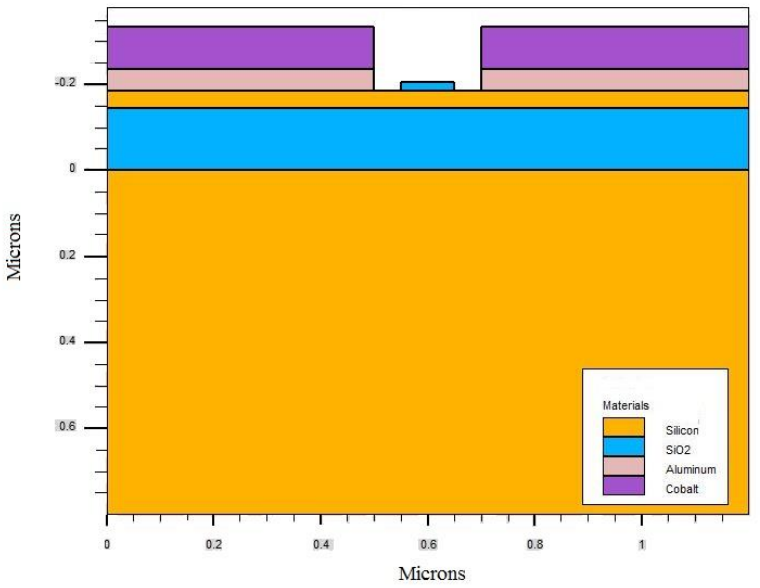

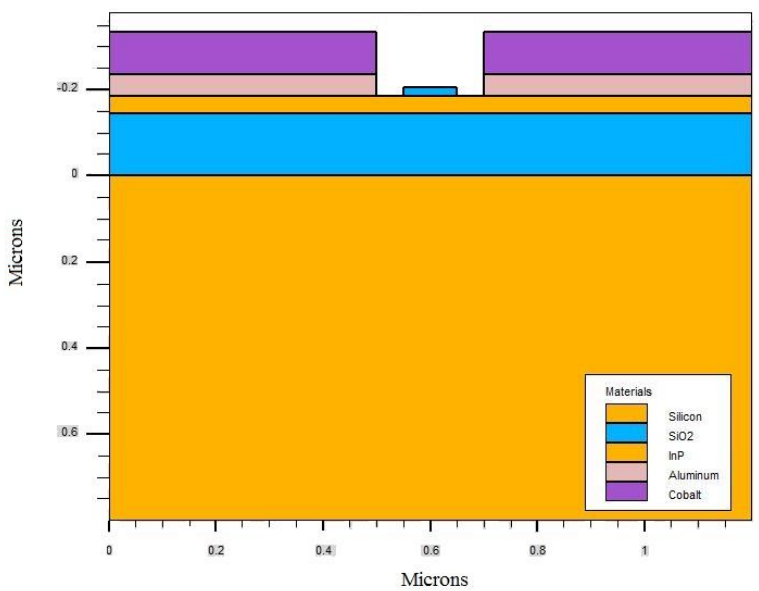

Fig. 3 SiNW-FET biosensor simulated in Silvaco ATLAS TonyPlot 2D cross-sectional (a) 2D crosssectional views along the SiNW- FET; (b) 2D cross-sectional views along the InPNW- FET. 


\section{Device modelling of the SiNW-FET and InPNW-FET biosensor}

In first step the investigation of the effect of different channel width on the electrical characteristic of the SiNW-FET(InPNW-FET) biosensor is performed by varying the width of the SiNW(InPNW-FET) at $40 \mathrm{~nm}, 60 \mathrm{~nm}$, and $70 \mathrm{~nm}$ and in the second step the investigation of the effect of different channel doping on the electrical characteristic of the SiNW-FET (InPNWFET) biosensor is performed by varying doping of the SiNW (InPNW-FET) at $0.1 \times 10^{14} \mathrm{~cm}^{-3}$, $1 \times 10^{14} \mathrm{~cm}^{-3}, 10 \times 10^{14} \mathrm{~cm}^{-3}$. The changes on the electrical resistance and $\mathrm{I}_{\mathrm{D}}$ due to different channel width and channel doping are observed from the TONYPLOT application in the Silvaco ATLAS. In addition, the surface of the channel is applied with negative $\mathrm{Q}_{\mathrm{F}}$ of

$0.1 \times 10^{12} \mathrm{~cm}^{-2},-0.5 \times 10^{12} \mathrm{~cm}^{-2}$, and $-1.0 \times 10^{12} \mathrm{~cm}^{-2}$ as representation of the existence of charged target DNA analyte that presents on SiNW-FET (InPNW-FET) biosensor upon detection [32]. The applied $\mathrm{Q}_{\mathrm{F}}$ has a effect on the electrical characteristic of current-voltage (I-V) and hole concentration for different channel width and channel doping of the SiNW-FET (InPNW-FET) biosensor. When $I_{D}$ changes we can determine the sensitivity of the device. So we can understand the performance of the biosensors with different channel width and channel doping to produce it for the future [33].

\section{Results and discussion}

\subsection{Channel width effect}

\subsubsection{Channel width effect on electrical characteristic}

The I-V characteristics of the SiNW-FET and InPNW-FET biosensor for different channel width are displayed as in Fig. 4a and Fig. 4b. However, the current generates by the component at a voltage of $-1 \mathrm{~V}$ in the values of $-12 \mu \mathrm{A},-16 \mu \mathrm{A}$ and $-17 \mu \mathrm{A}$ in the silicon state and the values of $-4 \mu \mathrm{A},-4.5 \mu \mathrm{A}$ and $-5 \mu \mathrm{A}$ in the indium state by changing the resistance with channel widths of $40 \mathrm{~nm}, 60 \mathrm{~nm}$ and $70 \mathrm{~nm}$. The increasing of $\mathrm{I}_{D}$ with the increase of the channel width of the device is well-correlated with the Eq. (17) which describe the relationship between 
electrical resistance, resistivity, and dimension of the SiNW (InPNW-FET) channel [24]:

$$
\mathrm{R}=\rho \cdot(\mathrm{L} / \mathrm{WT})
$$

Where $\mathrm{R}$ is the electrical resistance, $\rho$ is the resistivity, $\mathrm{L}$ is the length, $\mathrm{W}$ is the width, and $\mathrm{T}$ is the thickness of the SiNW (InPNW-FET) channel. From the Eq. (17), it can be seen that the R is indirectly proportional to the W of the SiNW (InPNW-FET) channel where the R is decreased with the increasing of SiNW (InPNW-FET) channel width of $40 \mathrm{~nm}, 60 \mathrm{~nm}$, and $70 \mathrm{~nm}$, respectively[34]. Since the Ohm's law $I_{D}$ versus $V_{D}$ characteristic and stated that the current (I) is indirectly proportional to the $\mathrm{R}$, the increase of channel width has increased the output $\mathrm{I}_{\mathrm{D}}$ as shown in Fig. 4a and Fig. 4b.
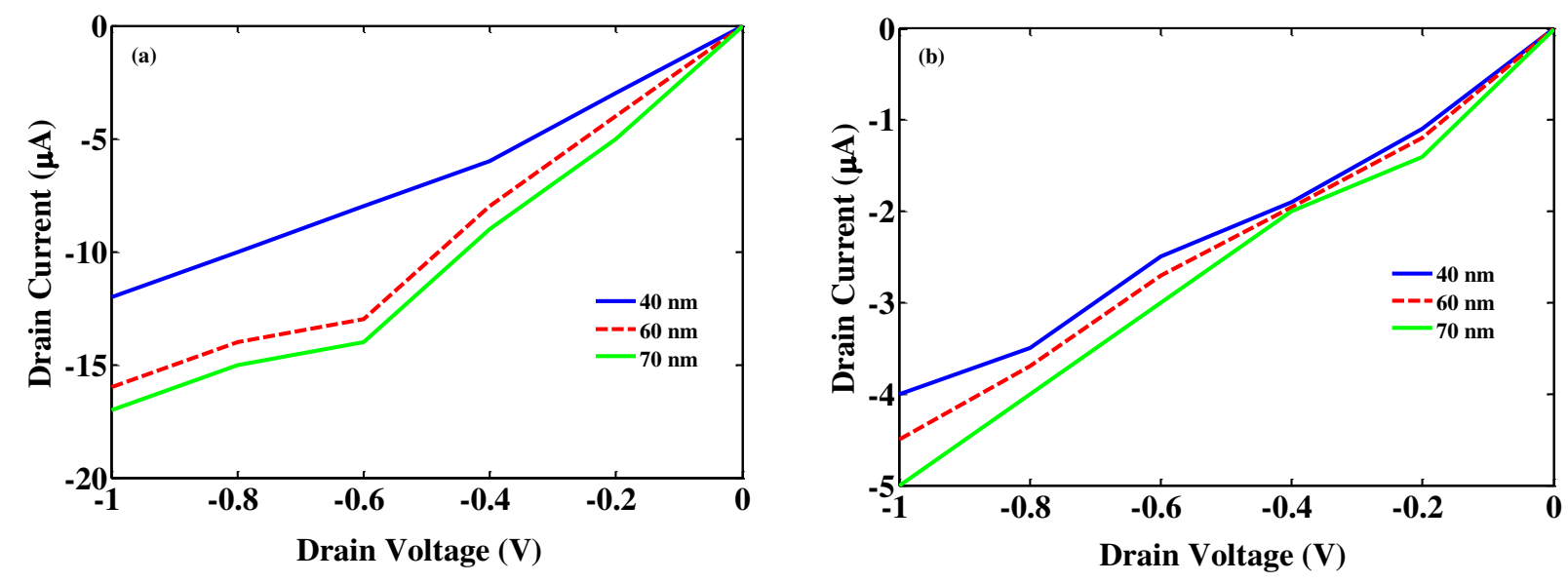

Fig. 4 Electrical characteristics of the (a) SiNW-FET; (b) InPNW biosensor simulated in Silvaco ATLAS due to the effect of different channel width of $40 \mathrm{~nm}, 60 \mathrm{~nm}$, and $70 \mathrm{~nm}$.

\subsubsection{Application of interface charge densities for difference channel widths}

The effect due to the application of different $Q_{F}$ values on the channel surface of the SiNWFET and InPNW-FET biosensor for different channel width of $40 \mathrm{~nm}, 60 \mathrm{~nm}$, and $70 \mathrm{~nm}$ towards the $I_{D}$ versus $V_{D}$ characteristics is shown as in Fig. 5a to Fig. 5f [35]. The surface of channel is applied with negative $Q_{F}$ of $-0.1 \times 10^{12} \mathrm{~cm}^{-2},-0.5 \times 10^{12} \mathrm{~cm}^{-2}$, and $-1 \times 10^{12} \mathrm{~cm}^{-2}$ to mimic the 
different concentrations of target biomolecules [28]. The values of $I_{D}$ are increased when more negative $Q_{F}$ values are applied onto the SiNW channel surface for every simulated device with different channel width as shown in Fig. 5a to Fig. 5c and onto the InPNW channel surface for every simulated device with different channel width as shown in Figs. 5d,5e and 5f. These changes in $I_{D}$ are due to the fact that the SiNW (InPNW) channel is doped with p-type dopant with doping concentration of $1 \times 10^{14} \mathrm{~cm}^{-3}$, which comprise of hole as majority carrier. In other word, the channel of the device is mainly comprised of positive charge.

More negative $\mathrm{Q}_{\mathrm{F}}$ on the $\mathrm{SiNW}$ (InPNW) channel surface has attracted the hole carriers underneath the channel surface and contribute to a good formation of hole conduction channel across the SiNW (InPNW). Therefore, more $I_{D}$ is allowed to flow from drain to source. These results show that all the simulated SiNW (InPNW) channel width is affected by the application of different $\mathrm{Q}_{\mathrm{F}}$ values applied on them, hence indicate that the SiNW (InPNW) channel detect different target analyte concentrations that will be captured by the bioreceptor immobilized onto the device. The detection will be signified by the relative change in $\mathrm{I}_{\mathrm{D}}$, which is the percentage difference of $I_{D}$ before and after detection [35].
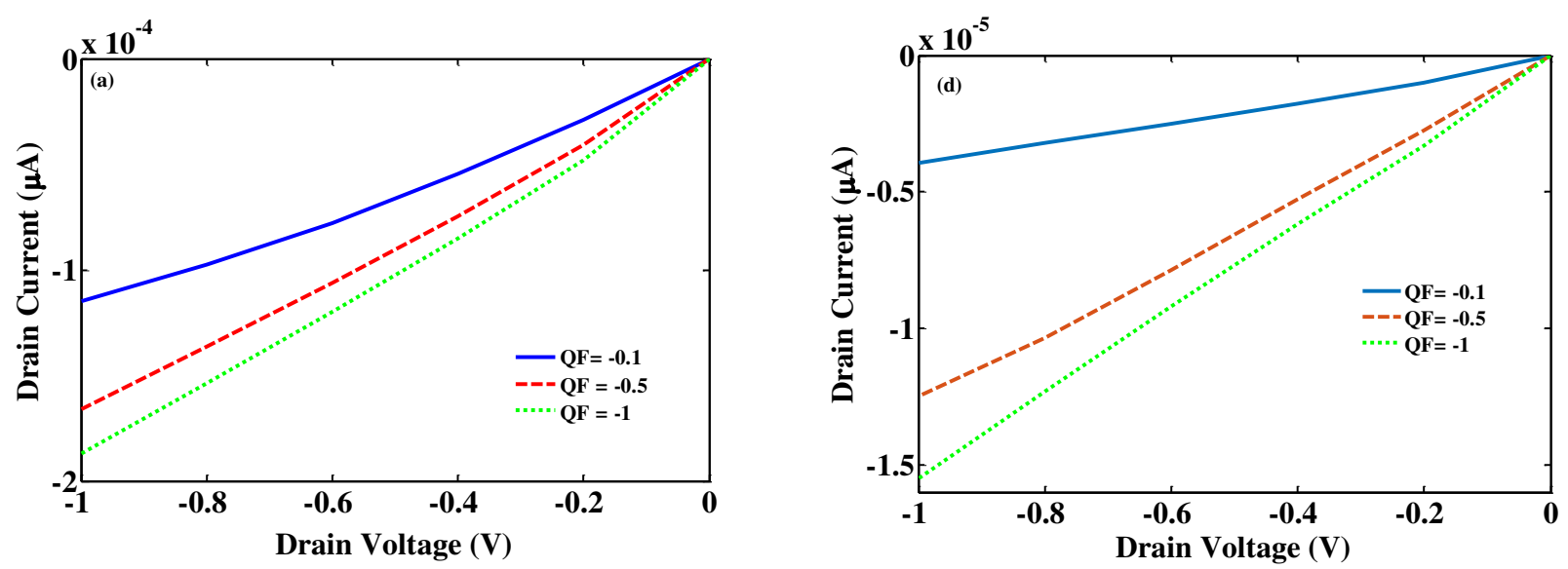

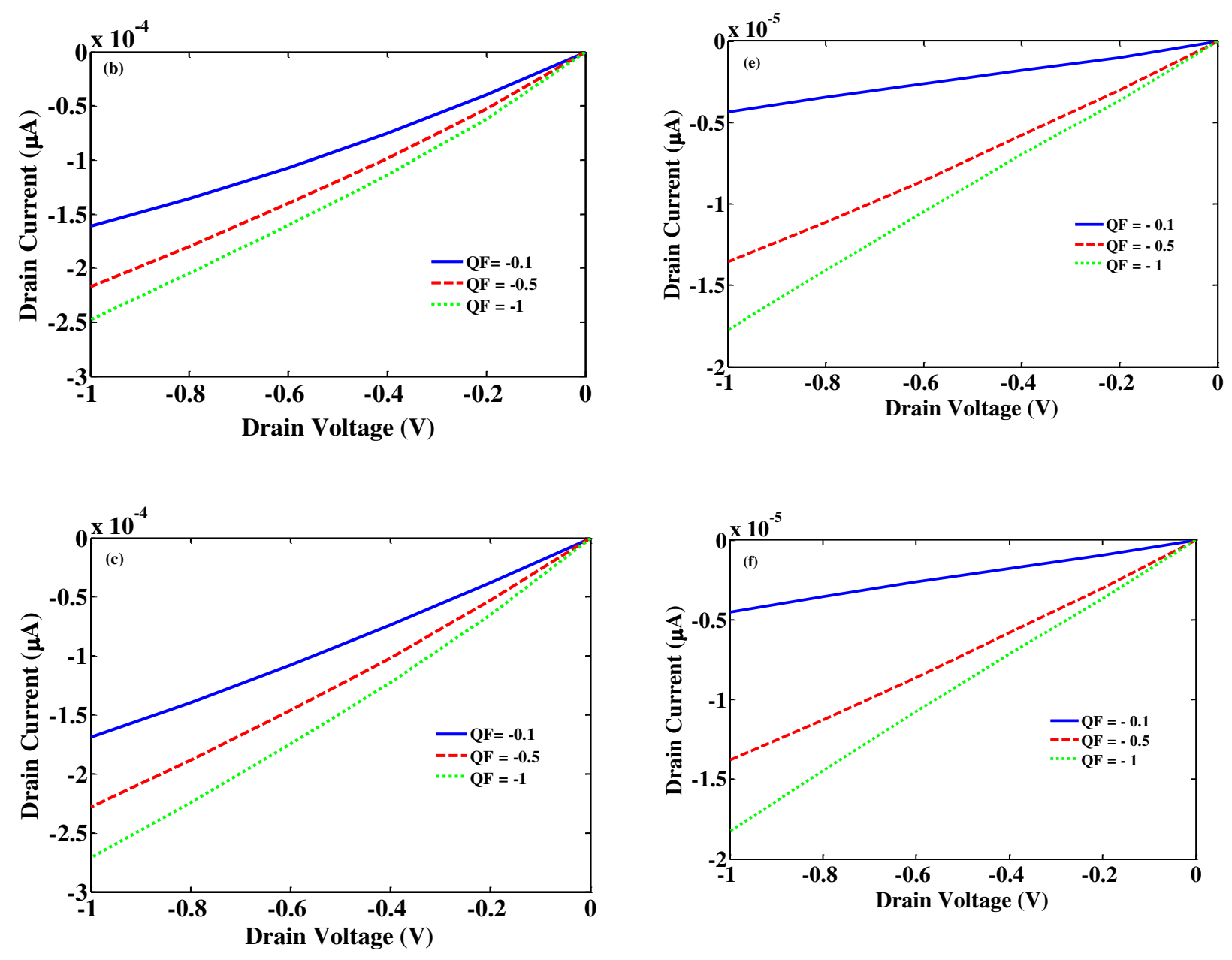

Fig. 5 Electrical characteristics in terms $I_{D}$ versus $V_{D}$ characteristics (a),(b),(c) SiNW-FET; (d),(e),(f) InPNW graph for biosensors at different channel width of $40 \mathrm{~nm}, 60 \mathrm{~nm}$, and $70 \mathrm{~nm}$ when applied with different $\mathrm{Q}_{\mathrm{F}}$ of $-0.1 \times 10^{12} \mathrm{~cm}^{-2},-0.5 \times 10^{12} \mathrm{~cm}^{-2}$, and $-1.0 \times 10^{12} \mathrm{~cm}^{-2}$.

\subsection{Channel doping effect}

\subsubsection{Channel doping effect on electrical characteristic}

The I-V characteristics of the SiNW-FET and InPNW-FET biosensor for different channel doping are displayed as in Fig. 6a and 6b. However, the current generates by the component at a voltage of $-1 \mathrm{~V}$ in the values of $-20 \mu \mathrm{A},-180 \mu \mathrm{A}$ and $-1400 \mu \mathrm{A}$ in the silicon state and the values of $-1.8 \mu \mathrm{A},-16 \mu \mathrm{A}$ and $-75 \mu \mathrm{A}$ In the indium state by changing the resistance with channel doping of $0.1 \times 10^{14} \mathrm{~cm}^{-3}, 1 \times 10^{14} \mathrm{~cm}^{-3}, 10 \times 10^{14} \mathrm{~cm}^{-3}$. The increasing of $\mathrm{I}_{\mathrm{D}}$ with the decreasing $\rho$ because of the increasing in the channel doping of the device is well-correlated 
with the Eq. (18) which describe the relationship between electrical resistance, resistivity, and dimension of the SiNW (InPNW-FET) channel [24]:

$$
\mathrm{R}=\rho \cdot(\mathrm{L} / \mathrm{WT})
$$

Where $\mathrm{R}$ is the electrical resistance, $\rho$ is the resistivity, $\mathrm{L}$ is the length, $\mathrm{W}$ is the width, and $\mathrm{T}$ is the thickness of the SiNW (InPNW-FET) channel. From the Eq. (18), it can be seen that the $\rho$ is directly proportional to the R of the SiNW (InPNW-FET) channel and because of inverse relation between $\rho$ and doping[36], the R is decreased with the increasing of SiNW (InPNW-FET) channel doping of $0.1 \times 10^{14} \mathrm{~cm}^{-3}, 1 \times 10^{14} \mathrm{~cm}^{-3}, 10 \times 10^{14} \mathrm{~cm}^{-3}$, respectively. Since the Ohm's law ID versus $V_{D}$ characteristic and stated that the current (I) is indirectly proportional to the $R$, the increase of channel doping has increased the output $\mathrm{I}_{\mathrm{D}}$ as shown in Fig. 6a and $6 \mathrm{~b}$.
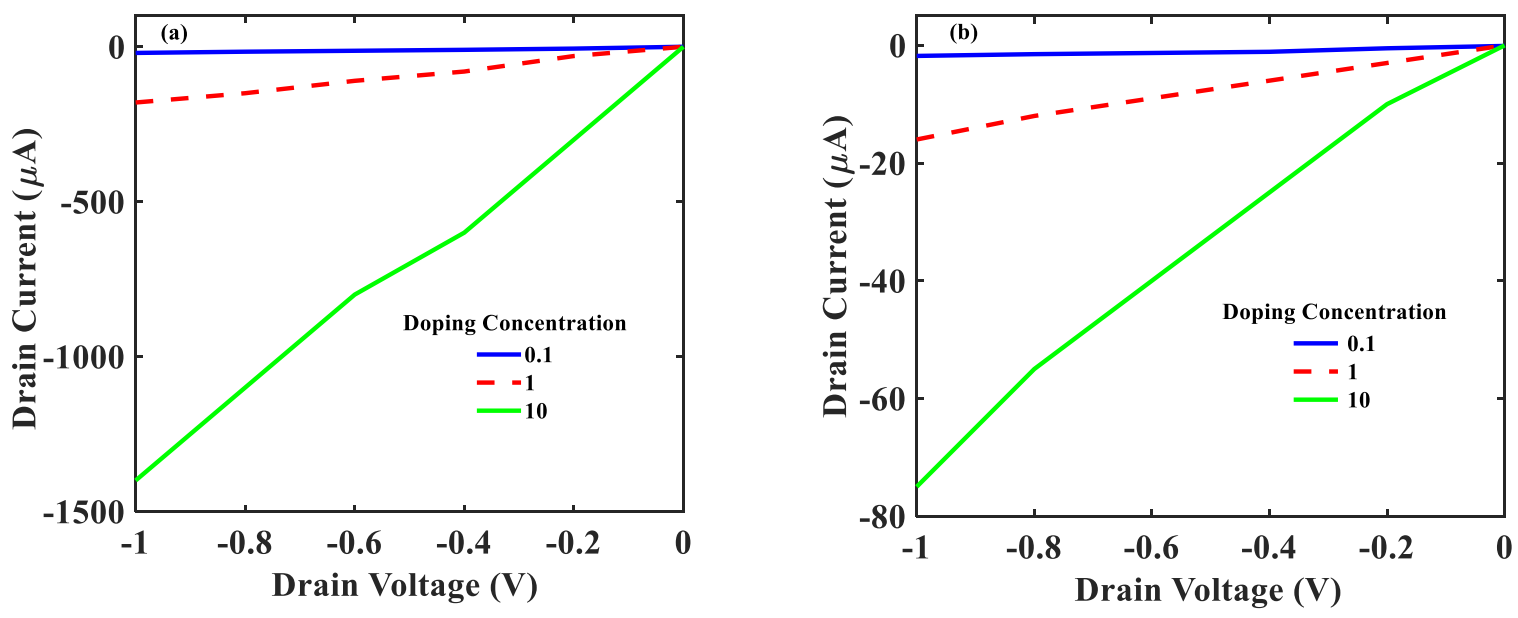

Fig. 6 Electrical characteristics of the (a) SiNW-FET; (b) InPNW-FET biosensor simulated in Silvaco ATLAS due to the effect of different channel doping of $0.1 \times 10^{14} \mathrm{~cm}^{-3}, 1 \times 10^{14} \mathrm{~cm}^{-3}, 10 \times 10^{14} \mathrm{~cm}^{-3}$.

\subsubsection{Application of interface charge densities for difference channel doping}

The effect due to the application of different $Q_{F}$ values on the channel surface of the SiNWFET and InPNW-FET biosensor for different channel doping of $0.1 \times 10^{14} \mathrm{~cm}^{-3}, 1 \times 10^{14} \mathrm{~cm}^{-3}$, $10 \times 10^{14} \mathrm{~cm}^{-3}$ towards the $I_{D}$ versus $V_{D}$ characteristics is shown as in Fig. 7 a to Fig. $7 \mathrm{f}$ [35]. The surface of channel is applied with negative $Q_{F}$ of $-0.1 \times 10^{12} \mathrm{~cm}^{-2},-0.5 \times 10^{12} \mathrm{~cm}^{-2}$, and $-1 \times 10^{12}$ 
$\mathrm{cm}^{-2}$ to mimic the different concentrations of target biomolecules [28]. The values of $I_{D}$ are increased when more negative $\mathrm{Q}_{\mathrm{F}}$ values are applied onto the SiNW channel surface for every simulated device with different channel doping as shown in Fig. 7a to Fig. 7c and onto the InPNW channel surface for every simulated device with different channel doping as shown in Figs. 7d ,7e and 7f. These changes in $I_{D}$ are due to the fact that the SiNW (InPNW) channel is doped with p-type dopant, which comprise of hole as majority carrier. In other word, the channel of the device is mainly comprised of positive charge.

More negative $\mathrm{Q}_{\mathrm{F}}$ on the $\mathrm{SiNW}$ (InPNW) channel surface has attracted the hole carriers underneath the channel surface and contribute to a good formation of hole conduction channel across the SiNW (InPNW). Therefore, more $I_{D}$ is allowed to flow from drain to source. These results show that all the simulated SiNW (InPNW) channel doping is affected by the application of different $\mathrm{Q}_{\mathrm{F}}$ values applied on them, hence indicate that the SiNW (InPNW) channel detect different target analyte concentrations that will be captured by the bioreceptor immobilized onto the device. The detection will be signified by the relative change in $I_{D}$, which is the percentage difference of $I_{D}$ before and after detection [35].
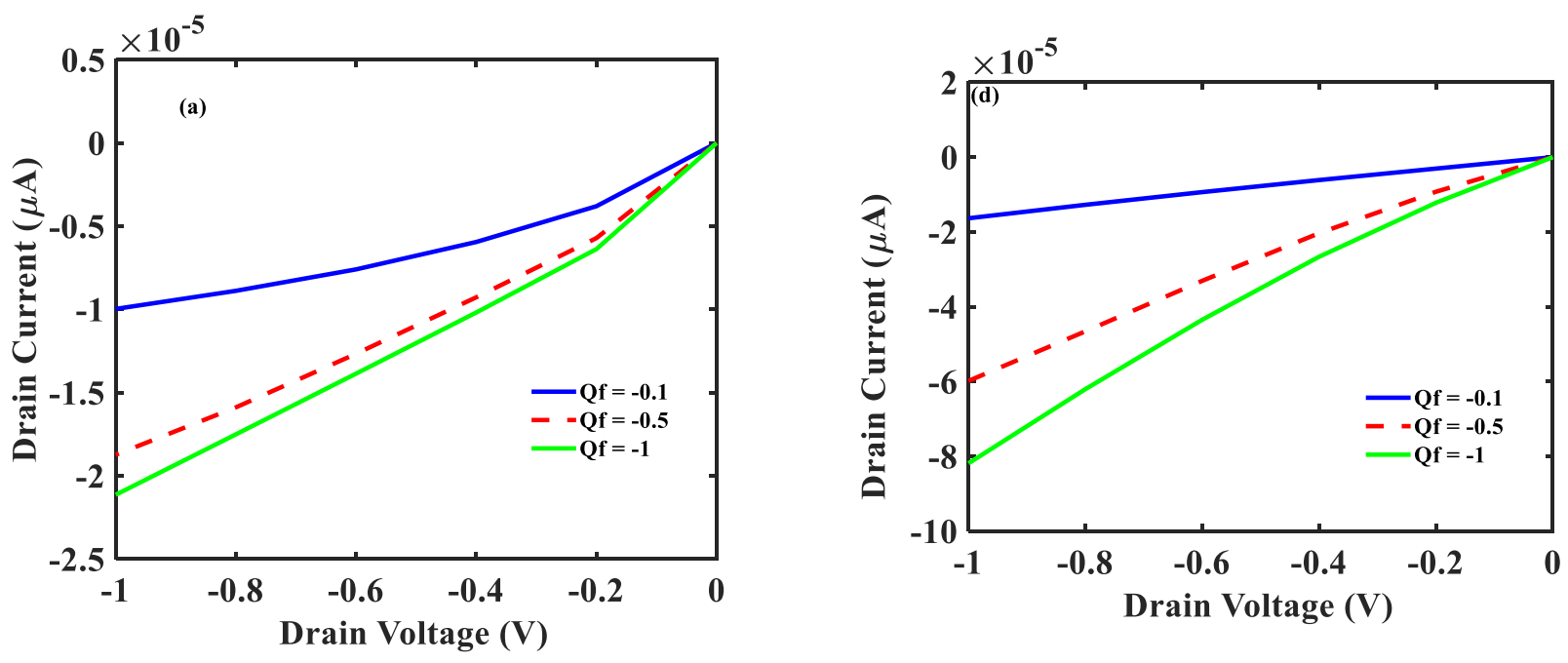

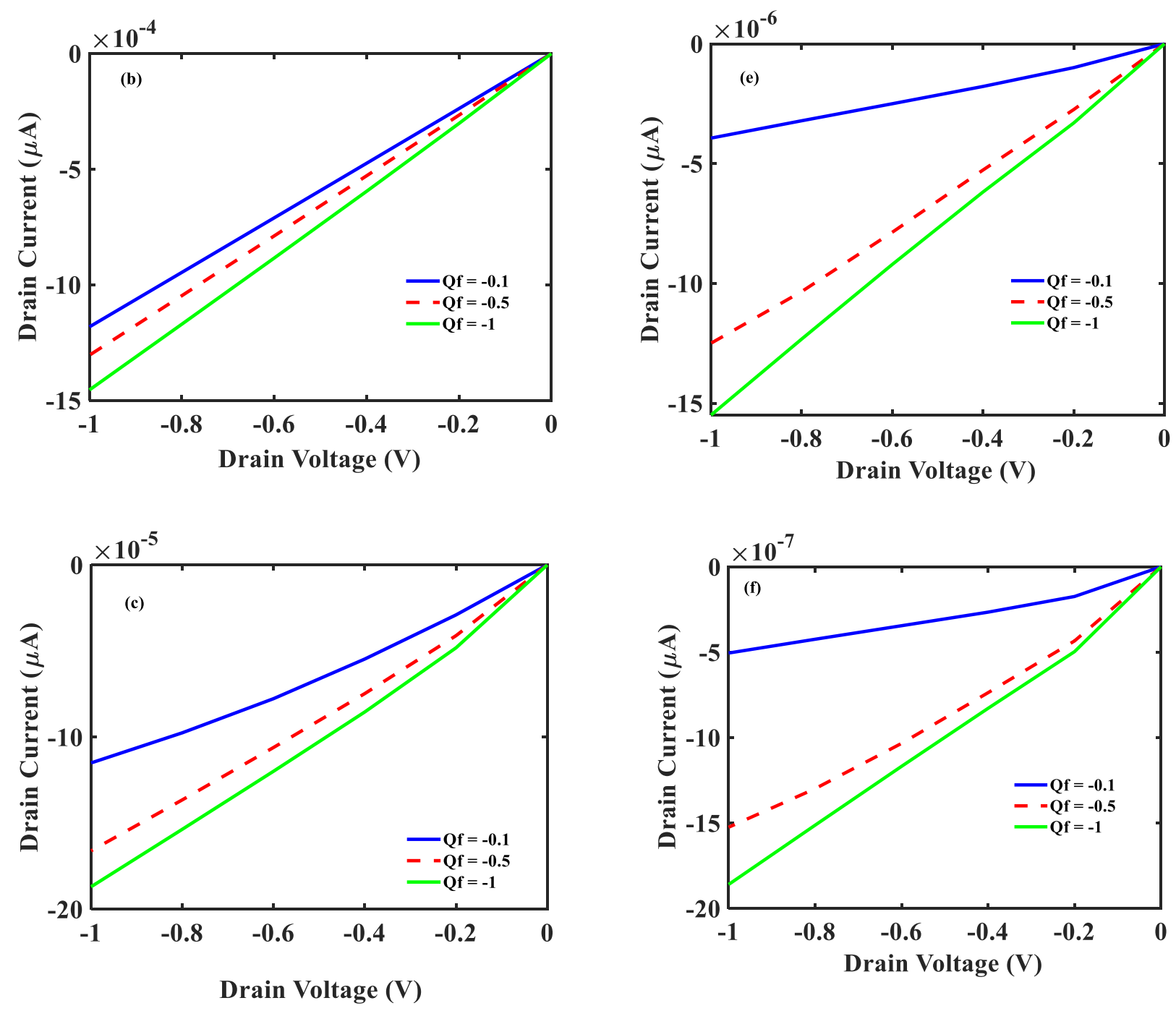

Fig. 7 Electrical characteristics in terms $I_{D}$ versus $V_{D}$ characteristics (a),(b),(c) SiNW- FET; (d),(e),(f) InPNW -FET graph for biosensors at different channel doping of $0.1 \times 10^{14} \mathrm{~cm}^{-3}, 1 \times 10^{14} \mathrm{~cm}^{-3}, 10 \times 10^{14}$ $\mathrm{cm}^{-3}$ when applied with different $Q_{F}$ of $-0.1 \times 10^{12} \mathrm{~cm}^{-2},-0.5 \times 10^{12} \mathrm{~cm}^{-2}$, and $-1.0 \times 10^{12} \mathrm{~cm}^{-2}$.

\subsection{Device performance analysis: sensitivity}

The accuracy of the measured output signal for a set of measurement with various analyte concentration through a straight-line equation is a feature that can be utilized to determine the sensitivity of a biosensor from a mathematic representation as in Eq. (19) [24]:

$$
\mathrm{y}=\mathrm{mx}+\mathrm{c}
$$

Where $\mathrm{c}$ is the analyte concentration, $\mathrm{y}$ is the output feedback, and $\mathrm{m}$ is the biosensor's sensitivity [17].

The device's sensitivity can be determined through calculation based on the ratio of difference of 
output $\mathrm{I}_{\mathrm{D}}\left(\Delta \mathrm{I}_{\mathrm{D}}\right)$ to difference of applied negative $\mathrm{Q}_{\mathrm{F}}\left(\Delta \mathrm{Q}_{\mathrm{F}}\right)$ on the SiNW-FET/ InPNW- FET surface for the three channel widths or for the three channel doping as in Eq. (20) [24]:

$$
\mathrm{m}=\Delta \mathrm{I}_{\mathrm{D}} / \Delta \mathrm{Q}_{\mathrm{F}}
$$

\subsubsection{Sensitivity of width change}

In order to analyze the effect of different channel widths on the sensitivity of the biosensor, the $I_{D}$ versus negative $Q_{F}$ is plotted in Fig. 8a and $8 b$ for channel width from $40 \mathrm{~nm}$ to $70 \mathrm{~nm}$ with ptype dopant at concentration of $1 \times 10^{14} \mathrm{~cm}^{-3}$. With the decreasing of channel width from $70 \mathrm{~nm}$ to $40 \mathrm{~nm}$, the SiNW biosensor's sensitivity has significantly increased from $1.5 \mu \mathrm{A} / \mathrm{cm}^{-2}$ to 3.2 $\mu \mathrm{A} / \mathrm{cm}^{-2}$, and the InPNW biosensor's sensitivity has significantly increased from $0.78 \mu \mathrm{A} / \mathrm{cm}^{-2}$ to $2.4 \mu \mathrm{A} / \mathrm{cm}^{-2}$, respectively. These results show that more than $120 \%$ increase of sensitivity for the SiNW-FET and InPNW-FET biosensor. Be carefule that the SiNW/InPNW should not be designed with very short channel width since it introduces very high resistance of SiNW/InPNW which may reduce the flow of current across the channel from drain to source.
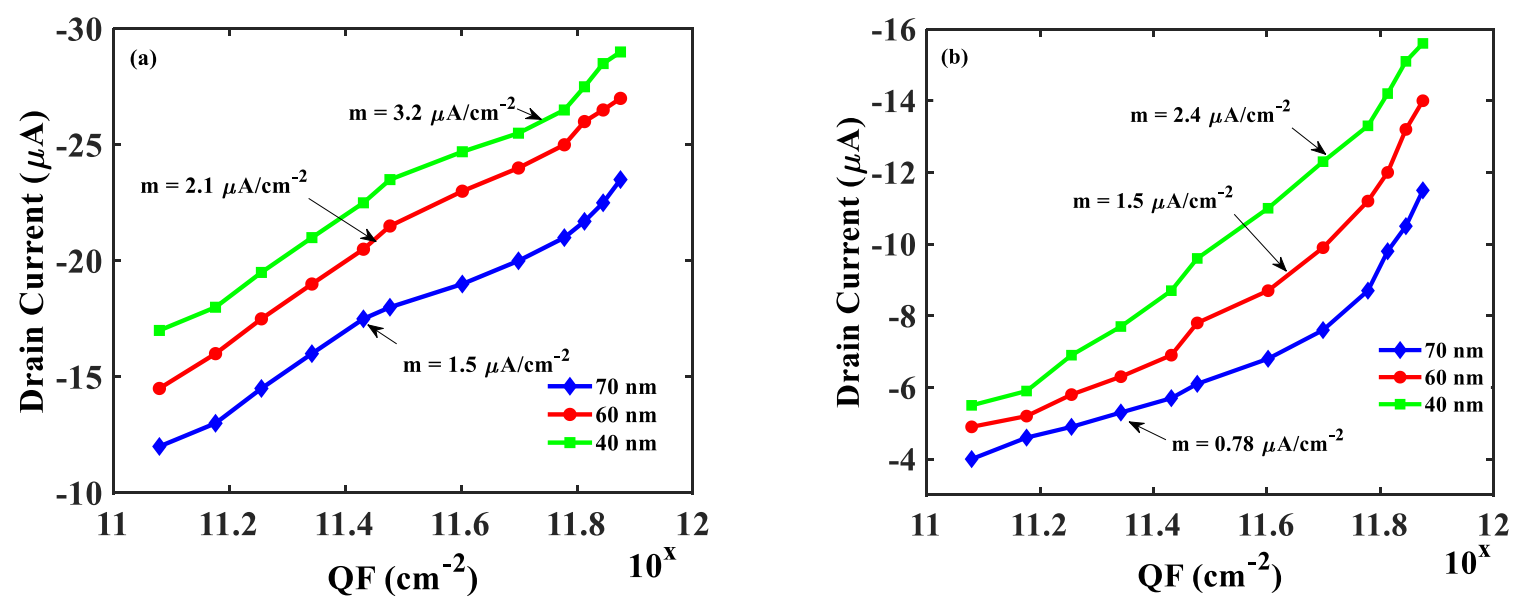

Fig. 8 Device performance analysis $I_{D}$ versus negative $Q_{F}$ to determine the sensitivity of the (a) SiNW; (b) InPNW with different channel width of $40 \mathrm{~nm}, 60 \mathrm{~nm}$, and $70 \mathrm{~nm}$. 


\subsubsection{Sensitivity of doping change}

In order to analyze the effect of doping concentration on the sensitivity of the biosensor, the $\mathrm{I}_{\mathrm{D}}$ versus negative $Q_{F}$ for different channel doping is plotted in Fig. 9a and 9b. With the decreasing of channel doping from $10 \times 10^{14} \mathrm{~cm}^{-3}$ to $0.1 \times 10^{14} \mathrm{~cm}^{-3}$, the SiNW biosensor's sensitivity(m) has significantly increased from $2.5 \mu \mathrm{A} / \mathrm{cm}^{-2}$ to $3.6 \mu \mathrm{A} / \mathrm{cm}^{-2}$ and the InPNW biosensor's sensitivity(m) has significantly increased from $1.8 \mu \mathrm{A} / \mathrm{cm}^{-2}$ to $2.8 \mu \mathrm{A} / \mathrm{cm}^{-2}$, respectively. This result shows that more than $80 \%$ increasing of sensitivity for the SiNW-FET and InPNW-FET biosensor. Be careful that the SiNW/InPNW channel should not be designed with low channel doping since it introduces very high resistance of SiNW/InPNW which may reduce the flow of current across the channel from drain to source.
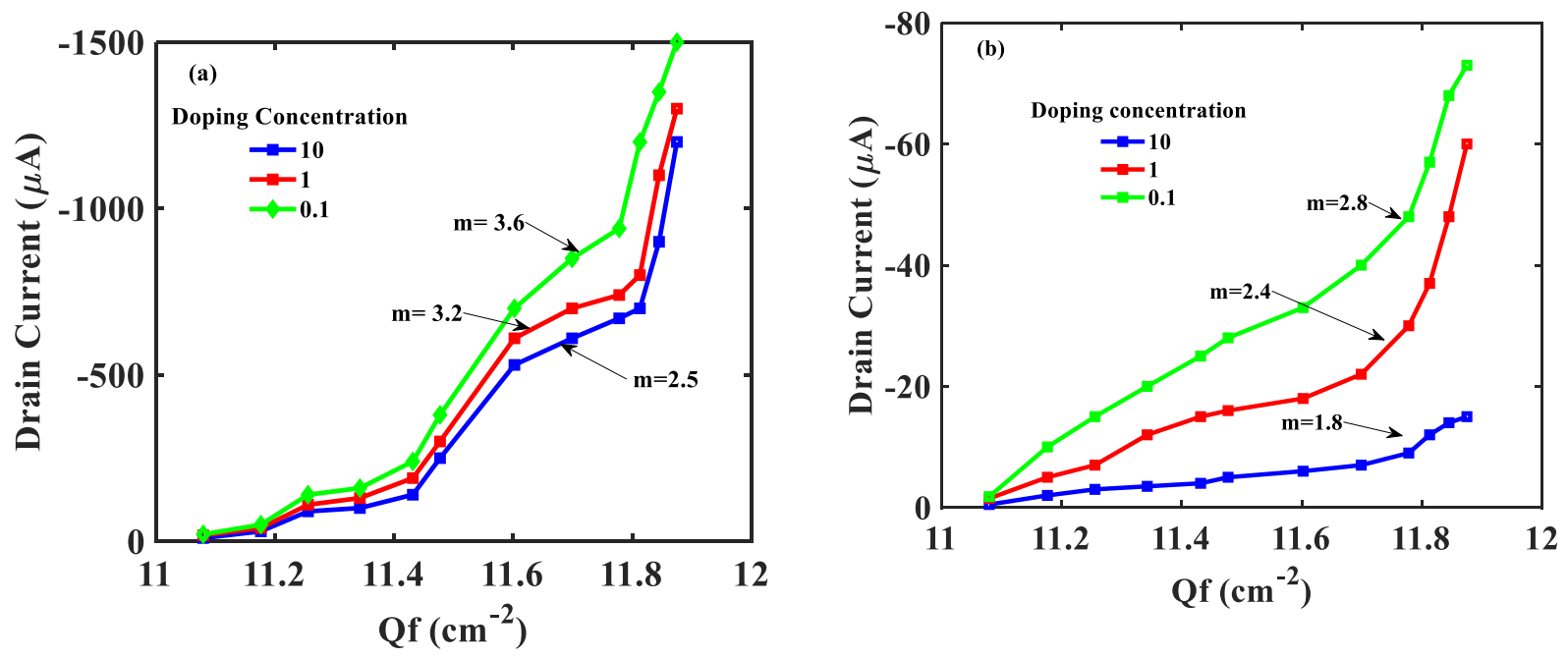

Fig. 9 Device performance analysis $I_{D}$ versus negative $Q_{F}$ to determine the sensitivity $(m)$ of the (a) SiNW; (b) InPNW with different channel doping of $0.1 \times 10^{14} \mathrm{~cm}^{-3}, 1 \times 10^{14} \mathrm{~cm}^{-3}, 10 \times 10^{14} \mathrm{~cm}^{-3}$.

Even though target analytes bind to the surface of the SiNW/InPNW, the change of $I_{D}$ will be kept at minimal since the SiNW/InPNW is high in resistance [37]. Therefore, in this simulation, the shortest $\mathrm{SiNW} / \mathrm{InPNW}$ channel with the width of $40 \mathrm{~nm}$ and the lowest SiNW channel doping of $0.1 \times 10^{14} \mathrm{~cm}^{-3}$ has demonstrated the best sensitivity compared to the other channels [15]. The 
result shows good improvement in SiNW when compares to the InPNW channels, respectively. Hence, as you can see in Table 2 and Table 3, among the three channels with different channel width and doping which have been simulated for both of the SiNW-FET and InPNW- FET, the increasing of channel doping causes decreasing of sensitivity $(\mathrm{m})$ and the increasing of channel width causes decreasing of sensitivity(m) and as a result the channel width of $40 \mathrm{~nm}$ with the lowest channel doping of $0.1 \times 10^{14} \mathrm{~cm}^{-3}$ can be considered with high sensitivity(m) for the fabrication of the actual and ideal device [38].

Table. 2 Comparing the sensitivity $\left(\mu \mathrm{A} / \mathrm{cm}^{-2}\right)$ of SiNW-FET with different width and doping values

\begin{tabular}{|c|c|c|c|}
\hline \multirow{2}{*}{ Doping $\left(\mathrm{cm}^{-3}\right)$} & \multicolumn{3}{|c|}{ Width $(\mathrm{nm})$} \\
\cline { 2 - 4 } & $40 \mathrm{~nm}$ & $60 \mathrm{~nm}$ & $70 \mathrm{~nm}$ \\
\hline $0.1 \times 10^{14}$ & 3.6 & 2.8 & 2.1 \\
\hline $1 \times 10^{14}$ & 3.2 & 2.1 & 1.5 \\
\hline $10 \times 10^{14}$ & 2.5 & 1.8 & 1.4 \\
\hline
\end{tabular}

Table. 3 Comparing the sensitivity $\left(\mu \mathrm{A} / \mathrm{cm}^{-2}\right)$ of InPNW-FET with different width and doping values

\begin{tabular}{|c|c|c|c|}
\hline \multirow{2}{*}{ Doping $\left(\mathrm{cm}^{-3}\right)$} & \multicolumn{3}{|c|}{ Width $(\mathrm{nm})$} \\
\cline { 2 - 4 } & $40 \mathrm{~nm}$ & $60 \mathrm{~nm}$ & $70 \mathrm{~nm}$ \\
\hline $0.1 \times 10^{14}$ & 2.8 & 1.9 & 1.3 \\
\hline $1 \times 10^{14}$ & 2.4 & 1.5 & 0.78 \\
\hline $10 \times 10^{14}$ & 1.8 & 1.1 & 0.65 \\
\hline
\end{tabular}

\section{Conclusion}

In conclusion, the effect of different SiNW and InPNW channel width with different channel doping towards the electrical characteristics has been understood by using the device numerical modelling tool, which is Silvaco ATLAS. The decreasing of the width and doping has contributed to the increase of electrical resistance at the channel region. Due to the fact that the electrical resistance is indirectly proportional to the output current based on the Ohm's law, it can be concluded that with the decreasing of the channel width and doping also has caused reduction of the output $\mathrm{I}_{\mathrm{D}}$ of the NW-FET device. In addition, simulations of the biomolecules 
detection have been performed on the NW-FET biosensor by using negative $\mathrm{Q}_{\mathrm{F}}$ as a representation of the target analyte. The introduction of negative $\mathrm{Q}_{F}$ on the surface of the channel has attracted the hole carriers inside the p-type SiNW, contributing to a better formation of hole conduction channel, which further increase the $I_{D}$ flow from drain to source region. The quantity of negative $Q_{F}$ determine the $I_{D}$ values that flows along the channel. These changes in $I_{D}$ is a representation of the target analyte concentration which is detected by the biosensor. The channel width of $40 \mathrm{~nm}$ with doping concentration of $0.1 \times 10^{14} \mathrm{~cm}^{-3}$ has shown an improvement on the performance of the SiNW-FET and InPNW biosensor with the sensitivity $3.6 \mu \mathrm{A} / \mathrm{cm}^{-2}$ and $2.8 \mu \mathrm{A} / \mathrm{cm}^{-2}$ respectively. These obtained results are for the sake of understanding the behavior of the SiNW-FET in comparison with InPNW-FET biosensor by altering its dimension and doping concentration, and may be used as a reference for the fabrication of the actual SiNW or InPNW biosensor in the future.

\section{References}

[1] Y. Hashim and M. N. Shakib, "A new factor for fabrication technologies evaluation for silicon nanowire transistors," Telkomnika, vol. 18, no. 5, pp. 2597-2605, 2020.

[2] F. C. Christopher, P. S. Kumar, F. J. Christopher, G. J. Joshiba, and P. Madhesh, "Recent advancements in rapid analysis of pesticides using nano biosensors: A present and future perspective," Journal of Cleaner Production, p. 122356, 2020.

[3] E. Ekrami, M. Pouresmaieli, P. Shariati, and M. Mahmoudifard, "A review on designing biosensors for the detection of trace metals," Applied Geochemistry, p. 104902, 2021.

[4] Y. Saylan, Ö. Erdem, S. Ünal, and A. Denizli, "An alternative medical diagnosis method: Biosensors for virus detection," Biosensors, vol. 9, no. 2, p. 65, 2019.

[5] E. V. R. Campos et al., "Recent Developments in Nanotechnology for Detection and Control of Aedes aegypti-Borne Diseases," Frontiers in Bioengineering and Biotechnology, vol. 8, p. 102, 2020.

[6] K.-I. Chen, B.-R. Li, and Y.-T. Chen, "Silicon nanowire field-effect transistor-based biosensors for biomedical diagnosis and cellular recording investigation," Nano today, vol. 6, no. 2, pp. 131-154, 2011.

[7] D. P. Tran, T. T. T. Pham, B. Wolfrum, A. Offenhäusser, and B. Thierry, "CMOScompatible silicon nanowire field-effect transistor biosensor: Technology development toward commercialization," Materials, vol. 11, no. 5, p. 785, 2018.

[8] M. Nuzaihan et al., "Electrical detection of dengue virus (DENV) DNA oligomer using silicon nanowire biosensor with novel molecular gate control," Biosensors and Bioelectronics, vol. 83, pp. 106-114, 2016.

[9] N. Chartuprayoon, M. Zhang, W. Bosze, Y.-H. Choa, and N. V. Myung, "One-dimensional nanostructures based bio-detection," Biosensors and Bioelectronics, vol. 63, pp. 432-443, 2015. 
[10] M. Mathew, S. Radhakrishnan, A. Vaidyanathan, B. Chakraborty, and C. S. Rout, "Flexible and wearable electrochemical biosensors based on two-dimensional materials: Recent developments," Analytical and Bioanalytical Chemistry, pp. 1-36, 2020.

[11] A. S. Maghsoudi, S. Hassani, K. Mirnia, and M. Abdollahi, "Recent Advances in Nanotechnology-Based Biosensors Development for Detection of Arsenic, Lead, Mercury, and Cadmium," International Journal of Nanomedicine, vol. 16, p. 803, 2021.

[12] J. Singhal, S. Verma, S. Kumar, and D. Mehrotra, "Recent Advances in Nano-Bio-Sensing Fabrication Technology for the Detection of Oral Cancer," Molecular Biotechnology, pp. 124, 2021.

[13] L. Manjakkal, D. Szwagierczak, and R. Dahiya, "Metal oxides based electrochemical pH sensors: Current progress and future perspectives," Progress in Materials Science, vol. 109, p. $100635,2020$.

[14] A. Ros, "Electric Field Driven Migration and Separation in the Microenvironment," Arizona State University, 2020.

[15] D. Rani, V. Pachauri, and S. Ingebrandt, "Silicon Nanowire Field-Effect Biosensors," in Label-Free Biosensing: Springer, 2018, pp. 27-57.

[16] S. Choi et al., "Experimental extraction of stern-layer capacitance in biosensor detection using silicon nanowire field-effect transistors," Current Applied Physics, vol. 20, no. 6, pp. 828-833, 2020.

[17] P. Bergveld, "Thirty years of ISFETOLOGY: What happened in the past 30 years and what may happen in the next 30 years," Sensors and Actuators B: Chemical, vol. 88, no. 1, pp. 120, 2003.

[18] R. Van Hal, J. Eijkel, and P. Bergveld, "A general model to describe the electrostatic potential at electrolyte oxide interfaces," Advances in colloid and interface science, vol. 69, no. 1-3, pp. 31-62, 1996.

[19] R. Afrasiabi, "Silicon nanoribbon FET sensors: fabrication, surface modification and microfluidic integration," KTH Royal Institute of Technology, 2016.

[20] L. Stolze, J. B. Wagner, C. D. Damsgaard, and M. Rolle, "Impact of surface complexation and electrostatic interactions on $\mathrm{pH}$ front propagation in silica porous media," Geochimica et Cosmochimica Acta, vol. 277, pp. 132-149, 2020.

[21] J. Wang, D. Ye, Q. Meng, C. a. Di, and D. Zhu, "Advances in Organic Transistor-Based Biosensors," Advanced Materials Technologies, vol. 5, no. 7, p. 2000218, 2020.

[22] S.-J. Choi, D.-I. Moon, S. Kim, J. P. Duarte, and Y.-K. Choi, "Sensitivity of threshold voltage to nanowire width variation in junctionless transistors," IEEE Electron Device Letters, vol. 32, no. 2, pp. 125-127, 2010.

[23] H. Zhang et al., "Design and Fabrication of Silicon Nanowire-Based Biosensors with Integration of Critical Factors: Toward Ultrasensitive Specific Detection of Biomolecules," ACS Applied Materials \& Interfaces, vol. 12, no. 46, pp. 51808-51819, 2020.

[24] M. Fathil et al., "Numerical simulation of different silicon nanowire field-effect transistor channel lengths for biosensing application," in AIP Conference Proceedings, 2018, vol. 2045, no. 1: AIP Publishing LLC, p. 020007.

[25] D. Sadighbayan, M. Hasanzadeh, and E. Ghafar-Zadeh, "Biosensing based on field-effect transistors (FET): Recent progress and challenges," TrAC Trends in Analytical Chemistry, p. $116067,2020$.

[26] P. Namdari, H. Daraee, and A. Eatemadi, "Recent advances in silicon nanowire biosensors: synthesis methods, properties, and applications," Nanoscale research letters, vol. 11, no. 1, p. 406, 2016.

[27] S. Zafar et al., "Silicon nanowire field effect transistor sensors with minimal sensor-tosensor variations and enhanced sensing characteristics," Acs Nano, vol. 12, no. 7, pp. 65776587, 2018.

[28] U. Hashim, S. F. A. Rahman, M. N. M. Nor, and S. Salleh, "Design and process development of silicon nanowire based DNA biosensor using electron beam lithography," in 
2008 International Conference on Electronic Design, 2008: IEEE, pp. 1-6.

[29] M.-A. Doucey and S. Carrara, "Nanowire sensors in cancer," Trends in biotechnology, vol. 37, no. 1, pp. 86-99, 2019.

[30] F.-C. Liu, C. Li, J.-M. Guo, H.-F. Jiang, H.-L. You, and Y.-Q. Zhuang, "A High Sensitivity Biosensor Based On Vertically Stacked Silicon Nanosheet-FET," in 2020 IEEE 15th International Conference on Solid-State \& Integrated Circuit Technology (ICSICT), 2020: IEEE, pp. 1-3.

[31] S. Sang, Y. Wang, Q. Feng, Y. Wei, J. Ji, and W. Zhang, "Progress of new label-free techniques for biosensors: a review," Critical reviews in biotechnology, vol. 36, no. 3, pp. 465-481, 2016.

[32] S.-W. Lu, C.-H. Li, S. S. Imam, S.-M. Yang, M.-J. Fan, and G. Sheu, "DNA Biosensor Applications for Poly-Silicon Nanowire Field-Effect Transistors," in 2016 IEEE 16th International Conference on Bioinformatics and Bioengineering (BIBE), 2016: IEEE, pp. 182-185.

[33] F. Puppo, F. L. Traversa, M. Di Ventra, G. De Micheli, and S. Carrara, "Surface trap mediated electronic transport in biofunctionalized silicon nanowires," Nanotechnology, vol. 27, no. 34, p. 345503, 2016.

[34] N. Elfström, R. Juhasz, I. Sychugov, T. Engfeldt, A. E. Karlström, and J. Linnros, "Surface charge sensitivity of silicon nanowires: Size dependence," Nano Letters, vol. 7, no. 9, pp. 2608-2612, 2007.

[35] N. N. Reddy and D. K. Panda, "A comprehensive review on tunnel field-effect transistor (TFET) based biosensors: recent advances and future prospects on device structure and sensitivity," Silicon, pp. 1-16, 2020.

[36] J. Li, Y. Zhang, S. To, L. You, and Y. Sun, "Effect of nanowire number, diameter, and doping density on nano-FET biosensor sensitivity," ACS nano, vol. 5, no. 8, pp. 6661-6668, 2011.

[37] S. Hofbauer, J. Helm, C. Obinger, K. Djinović-Carugo, and P. G. Furtmüller, "Crystal structures and calorimetry reveal catalytically relevant binding mode of coproporphyrin and coproheme in coproporphyrin ferrochelatase," The FEBS journal, vol. 287, no. 13, pp. 27792796, 2020.

[38] T. C. Nguyen, "Readout Concepts for Label-Free Biomolecule Detection with Advanced ISFET and Silicon Nanowire Biosensors," 2018. 